\title{
Whether Adults with Flexible Flatfoot need the Treatment might be Better Depend on the Severity than on the Symptom
}

\author{
Jun Na Zhai, Jue Wang and Yu Sheng Qiu* \\ Department of Orthopaedics, First Affiliated Hospital of Xi'an Jiaotong University, China
}

Submission: February 10, 2017; Published: February 15, 2017

*Corresponding author: Yu Sheng Qiu, Department of Orthopaedics, First Affiliated Hospital of Xi'an Jiaotong University, Key Laboratory of Biomedical Information Engineering of Ministry of Education, Research Center of Rehabilitation Science and Technology, School of Life Science and Technology, Xi'an 710061, Shaanxi, PR China, China, Tel: +8618710571160; Email: yusheng.qiu@mail.xjtu.edu.cn

\begin{abstract}
Purpose: This study observed the plantar pressure between flexible flatfoot and normal foot on different walking conditions to find out if flexible flatfoot needs the treatment and how the plantar pressure change while walking upstairs and downstairs.

Subjects and Methods: Fifteen adults with mild flexible flatfoot, fifteen adults with severe flexible flatfoot and fifteen adults with normal foot were examined while walking on a level surface, walking up and down $10 \mathrm{~cm}$ and $20 \mathrm{~cm}$ stairs. The contact area and the load rate were acquired using the RSscan system. The repeated measures ANOVA was performed to analyze the data.

Results: Compared with normal foot, both contact area and load rate of severe flatfoot were significantly increased on different walking conditions. When walking down $10 \mathrm{~cm}$ and $20 \mathrm{~cm}$ stairs, the plantar data of both normal foot and flatfoot were significantly increased.

Conclusion: The plantar pressure of severe flexible flatfoot were significantly larger than that of normal foot on different walking conditions. In addition, the arches of both normal foot and flatfoot were obviously deformed when walking downstairs. It is therefore necessary to be treated for severe flexible flatfoot to prevent further deformation. Whether adults with flexible flatfoot need the treatment is depend on the severity but not the symptom.
\end{abstract}

Keywords: Flexible flat foot; Plantar pressure; Contact area; Load rate

\section{Introduction}

Flexible flatfoot is a common disease and whether adults with flexible flatfoot need the treatment has always been a controversy. Flexible flatfoot can be further divided into mild flexible flatfoot and severe flexible flatfoot. So far, previous studies did not observe the plantar pressure of both kinds respectively and they had only focused on the plantar pressure of walking on the level surface. However, the differences between mild flexible flatfoot and severe flexible flatfoot, and how the plantar pressure changes while walking upstairs or downstairs has not been studied [1-3].

We examined the contact area and load rate of mild flexible flatfoot, severe flexible flatfoot and normal foot while walking on a level surface, walking up and down $10 \mathrm{~cm}$ and $20 \mathrm{~cm}$ stairs to estimate how plantar pressure changed and further to find out if flexible flatfoot needs the treatment. All the patients have no symptom. The repeated measures ANOVA with a level of significance of $\mathrm{p}<0.05$ was performed using spss 13.0. The $95 \%$ confidence intervals (CIs) $(\mathrm{p}<0.05)$ was considered statistically significant.

With the progression of the disease, the arch will become flat further result in an increase of contact area and load rate. The load rate $(\mathrm{N} / \mathrm{ms})$ can be used to indicate the load-bearing ratio for one part of the foot per millisecond. The contact area (square centimeters)can be used to indicate the area of contact between one part of the foot and the ground.

The significant differences were found in contact area and load rate between severe flexible flatfoot and normal foot $(p<0.01)$, and between severe flexible flatfoot and mild flexible flatfoot $(p<0.01)$. While there was no significant difference between mild flexible flatfoot and normal foot in both data. ( $p>0.05$ ) In addition, there was no intersection of the $95 \%$ CIs of both data between severe flexible flatfoot and normal foot on 5 
different walking conditions. Furthermore, no intersection could be found between mild flexible flatfoot and normal foot when walking downstairs. Besides, the $95 \%$ CIs of downstairs of both data did not intersect with any other walking conditions not only in flatfoot but also in normal foot

The results implied that the plantar pressure of severe flexible flatfoot were significantly larger than that of normal foot. Although there was no difference between mild flexible flatfoot and normal foot when walking on the level surface and walking upstairs, the plantar pressure of mild flexible flatfoot did differ from the normal foot when walking downstairs. Additionally, the arches of both normal foot and flatfoot were obviously deformed when walking down $10 \mathrm{~cm}$ and $20 \mathrm{~cm}$ stairs [4-6].

\section{Conclusion}

Although the adults with severe flexible flatfoot did not have any symptom, they may still need treatment to prevent further deformation. Whether adults with flexible flatfoot need the treatment might be better depend on the severity than the symptom. However, further studies are necessary to analyze the plantar pressure of adults with flatfoot in other areas in the future.

\section{Acknowledgment}

We sincerely thank The Natural Science Foundation of China, numbered: H81371943, for surporting our work.

\section{References}

1. Demetracopoulos CA, Nair P, Malzberg A, Deland JT (2015) Outcomes of a Stepcut Lengthening Calcaneal Osteotomy for Adult-Acquired Flatfoot Deformity. Foot Ankle Int 36(7): 749-755.

2. Haddad SL, Myerson MS, Younger A, Anderson RB, Davis WH (2011) Symposium: Adult acquired flatfoot deformity. Foot Ankle Int 32(32): 95-111.

3. Liao S (2016) The effect of orthotic insole on coupling mechanism of flatfoot in Gait. Foot Ankle Surg 22(2): 111.

4. Son H (2013) The effect of backpack load on muscle activities of the trunk and lower extremities and plantar foot pressure in flatfoot. J Phys Ther Sci 25(11): 1383-1386.

5. Begg L, Mclaughlin P, Vicaretti M, Fletcher J, Burns J (2016) Total contact cast wall load in patients with a plantar forefoot ulcer and diabetes. J Foot Ankle Res 9(1): 1-8.

6. Fernándezseguín LM, DiazMancha JA, Sánchez RR, Escamilla ME, Gómez MB, et al. (2014) Comparison of plantar pressures and contact area between normal and cavus foot. Gait Posture 39(2): 789-792.

\section{Your next submission with Juniper Publishers} will reach you the below assets

- Quality Editorial service

- Swift Peer Review

- Reprints availability

- E-prints Service

- Manuscript Podcast for convenient understanding

- Global attainment for your research

- Manuscript accessibility in different formats ( Pdf, E-pub, Full Text, Audio)

- Unceasing customer service

Track the below URL for one-step submission https://juniperpublishers.com/online-submission.php 